\title{
Un mapa de intervenciones del sector público en patrimonio cultural facilita la formación e investigación de profesionales
}

\begin{abstract}
El proyecto Lista Blanca (SIG Blanco) busca generar conocimiento transformando la recopilación de licitaciones desarrolladas en España en materia de patrimonio cultural desde el Sector Público en un mapa visual. Esta herramienta es una fotografía del año 2019, que crea una imagen fija de licitaciones anunciadas en la Plataforma de Contratación del Sector Público y en plataformas autonómicas de forma que dicha información pueda ser utilizada con fines formativos y de investigación.
\end{abstract}

Jimena Calleja García, Rosa Tera Saavedra, Marta González Casanovas | ACRE

Url de la contribución <www.iaph.es/revistaph/index.php/revistaph/article/view/4550>

En el marco de las Subvenciones de Ayudas para laAcción y Promoción Cultural 2019, la Asociación Profesional de Conservadores-Restauradores de España (ACRE) fue concesionaria con el Proyecto Lista Blanca (SIG Blanco): Intervenciones del Sector Público en Patrimonio Cultural para desarrollar una herramienta virtual de consulta y difusión.

El proyecto Lista Blanca (SIG Blanco) busca generar conocimiento transformando la recopilación de licitaciones desarrolladas en España en materia de patrimonio cultural desde el sector público en un mapa visual. Esta herramienta es una fotografía del año 2019, que crea una imagen fija de licitaciones anunciadas en la Plataforma de Contratación del Sector Público y en plataformas autonómicas de forma que dicha información pueda ser utilizada con fines formativos y de investigación. Esta publicación es virtual, alojada en el sitio web de $A C R E^{1}$ y abierta al público de forma gratuita.

Las licitaciones recogidas son el fruto de la búsqueda automatizada, que no sistemática, utilizando los sistemas de búsqueda semántica de las diferentes plataformas. En ellas se recopilan aspectos de la profesión de la conservación-restauración pero se amplía a muchas otras profesiones relacionadas con el patrimonio cultural como puede ser, por ejemplo, la archivística y documentación, la arqueología o los servicios a museos.

Se han realizado cerca de 200 registros en todo el territorio nacional, que se muestran en un plano inicial con chinchetas de colores correspondientes a las 17 categorías que se definen según el tipo de intervención especificado en los pliegos. Igualmente se pueden consultar en su categoría específica, en un mapa donde las georrefencias de la leyenda se relacionan en este caso con entidad contratante que saca la licitación. Cada registro corresponde a una licitación. Su ficha da acceso a los datos de una manera resumida: inversión con y sin IVA, fecha límite de presentación, empresa adjudicataria... y en unos puntos laterales desplegables la documentación asociada a la licitación: anuncio de licitación, pliegos, proyectos, información de valoraciones, informe sobre ofertas incursas en presunción de anormalidad y adjudicación.

La utilidad de esta herramienta está principalmente orientada al campo de la formación y la investigación por varias razones: no es un archivo de licitaciones completo, no se introducen las licitaciones según aparecen y el proyecto se limita a licitaciones del 2019. Sin embargo, da a conocer una de las salidas profesionales de la profesión que tiene relación con la administración pública y con las leyes que la rigen. Con este objetivo se ha creado varias pestañas: organismos de contratación, plataformas de contratación del sector público donde se resumen sus características principales para facilitar su uso, breve aproximación a la Ley de Contratación del Sector Público, con las obligaciones de las administraciones en la contratación y expedientes de patrimonio cultural en licitaciones con un interés especial para el estudio, donde se muestran los proyectos, valoraciones, 
bajas anómalas, contratos menores, contratos desiertos y desestimientos. Todos estos usos son igualmente de utilidad a los profesionales tanto autónomos como empresas, porque permiten la comparación de proyectos y mejora de los propios, para la búsqueda de empresas, para buscar estrategias de concursar a licitaciones o conocer cómo realizan las valoraciones en las distintas administraciones públicas.

Fuera de estos objetivos del proyecto, queremos también hacer una reflexión sobre posibles utilidades que podrían realizarse con un sistema de recopilación sistematizada. Queremos llamar la atención sobre las posibles utilidades que daría una comparativa rápida a golpe de vista del tipo de inversión pública, sabiendo si se realiza desde entidades locales, autonómicas o estatales, siendo posible marcar la tendencia de las inversiones de ciertas administraciones hacia un tipo de categoría o, al contrario, se podría mostrar un equilibrio en el tipo de inversiones, y podría ponerse en evidencia o buscar las causas de por qué en determinados espacios no aparece inversión pública, pudiendo esto estar relacionado con tres factores muy importantes: la actual función de plataformas virtuales de contratación para la difusión y transparencia, la falta de correcta categorización de los $\mathrm{CPV}^{2}$ en donde se pierden datos en la búsqueda auto-
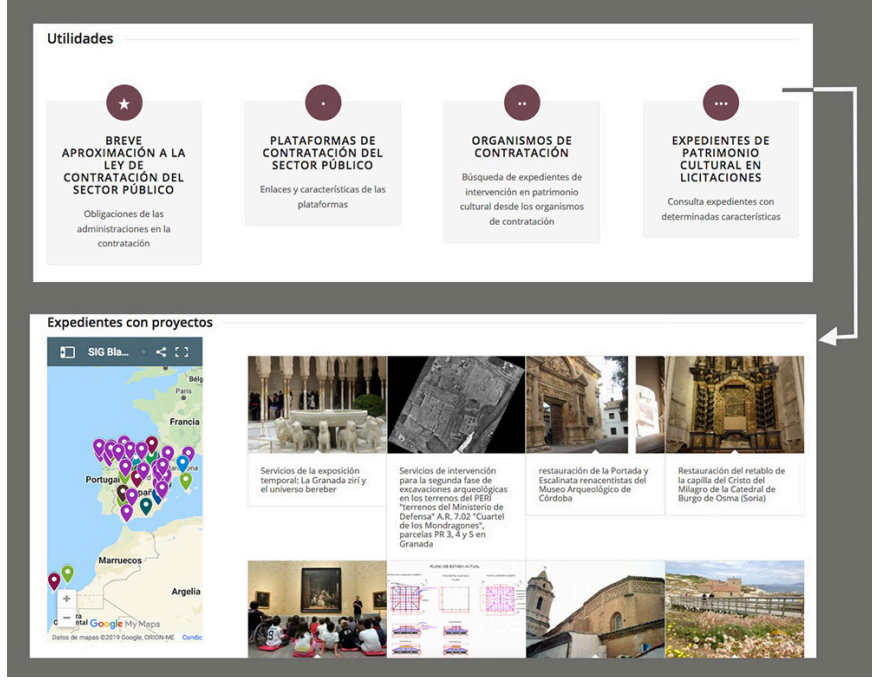

Imágenes procedentes de la web de Sig Blanco correspondientes al apartado de formación, donde pinchando en Expedientes se despliega la ventana inferior

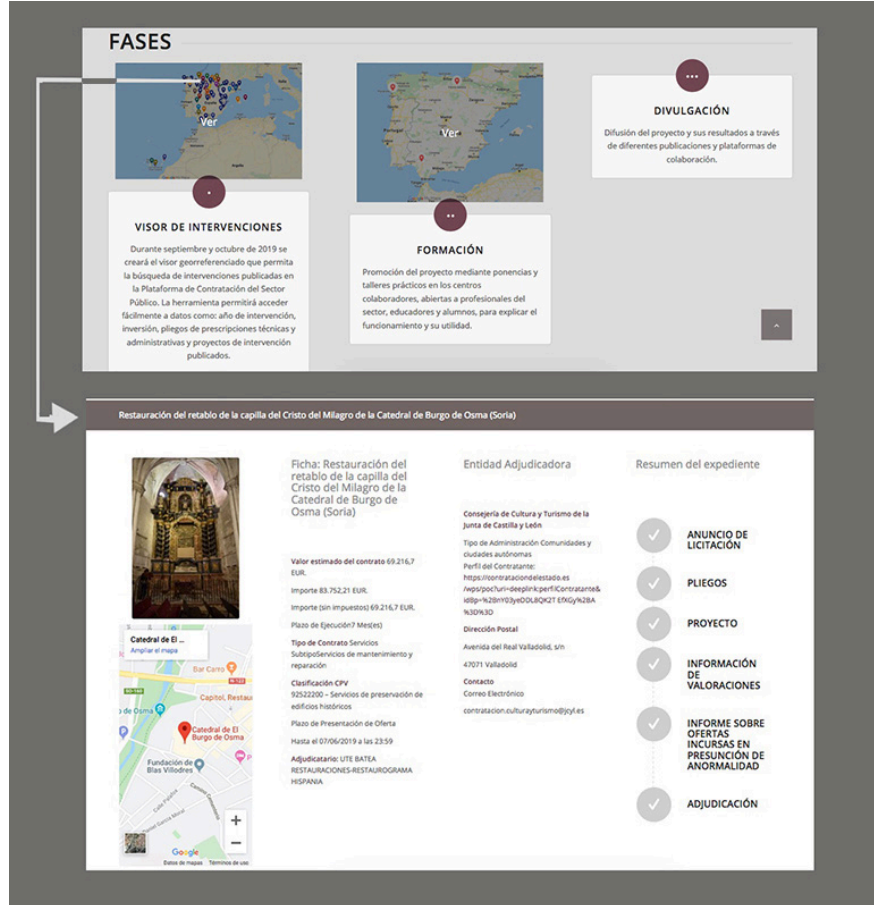

Imágenes procedentes del visor Sig Blanco: página principal con las fases y ventana que se despliega cuando se pincha en el enlace relacionado con una chincheta

matizada afectando a la exclusión de profesionales de la conservación y restauración en el acceso a estos servicios, o la falta de inversión pública.

Las utilidades de este tipo de plataformas georreferenciadas a nivel de gestión patrimonial pueden indicar también a qué tipo de bienes se llega y en qué forma o tipo de empleo. En algunos casos, la falta de inversión pública puede estar relacionada con una mayor inversión de capital privado, lo que no debe eximir a la administración pública de sus responsabilidades. Se puede relacionar directamente con la despoblación y la inversión pública en patrimonio, entender necesidades de conservar una categoría de bienes que parece desatendido con respecto a otras, se puede conocer cómo se contratan en las distintas autonomías si son obras mayores o menores, si se licita correctamente o se desconoce la profesión y se sustituye por otras como artesano, ingenieros, arquitectos..., es susceptible de servir para generar planes de gestión patrimonial más globales y completos. 
En esta plataforma se comprueba y respalda de forma material ejemplos reales de muchos aspectos que ha demandado ACRE, como asociación relacionada con la defensa de la profesión, por considerar lesivos a la profesión, ya sea por incorrección en las formas, por omisión o por desconocimiento. Algunos de estos aspectos son: el uso incorrecto de los códigos CPV; la necesidad de trabajar para conseguir que la Ley de Contratación del Sector Público no estrangule a las empresas de restauración con las exigencias de garantías financieras o las exigencias de experiencia curricular en los últimos 3 o 5 años en relación con los CPV; la necesidad de la inclusión de todas las titulaciones de conservación y restauración oficiales en los curriculum de las licitaciones; la vigilancia de las bajas económicas y todos aquellos aspectos que perjudican a la profesión y por ende al patrimonio cultural.

Por ello, en este aspecto, SIG Blanco quiere presentarse como prototipo que pueda convertirse en un modelo a replicar desde la Administración del Estado, donde el nombre de SIG hiciese honor al significado de sus siglas y realmente funcionase con una base de datos de fondo y un motor de búsqueda, que colgase de forma automática las licitaciones publicadas relacionadas con el patrimonio cultural y sus documentos asociados, de tal manera que fuese un buscador visual y herramienta intuitiva a nivel nacional. Esta herramienta facilitaría la transparencia en los procesos de concurso de las administraciones públicas, evitaría las licitaciones desiertas, y mejoraría la calidad de las intervenciones en patrimonio cultural al darse concursos con más de un participante.

Hasta marzo de 2020 este proyecto se presentará en distintos centros oficiales de formación de conservadores-restauradores (Escuelas Superiores de Conservación y Restauración de Bienes Culturales y Universidades con itinerario en Restauración), en centros profesionales de conservación y restauración y en algunas administraciones públicas.

\section{NOTAS}

1. https://asociacion-acre.org/proyectos/sig-blanco/ visorl

2. CPV (Common Procured Vocabulary / Vocabulario Común de Contratos Públicos) hace referencia al sistema de identificación y categorización de las actividades económicas utilizado en la Unión Europea para sacar a concurso público contrataciones. 